\title{
Anesthetic management of the ex utero intrapartum treatment (EXIT) procedure
} -A case report-

\author{
Heeseung Lee, Jung Wan Ryu, Dong Yeon Kim, and Guie Yong Lee \\ Department of Anesthesiology and Pain Medicine, School of Medicine, Ewha Womans University, Seoul, Korea
}

The ex utero intrapartum treatment (EXIT) procedure is a very rare technique performed in cases of fetal congenital malformations. The EXIT procedure increases the rate of survival at delivery by maintaining the uteroplacental circulation until the airway of the fetus is secured. To maintain the uteroplacental circulation, a higher dose of inhalational anesthetics and/or intravenous nitroglycerin can be used as compared to conventional Cesarean section. The aim of this report is to share our anesthetic experience during the EXIT procedure with members of the Korean society of anesthesiology for the first time, and to highlight the maternal implications of the use of inhalational anesthetics and nitroglycerin during Cesarean section for the EXIT procedure. (Korean J Anesthesiol 2010; 59: S154-S157)

Key Words: Cesarean delivery, Ex utero intrapartum treatment (EXIT), Fetal malformation, General anesthesia.

The ex utero intrapartum treatment (EXIT) procedure is an uncommon technique that is implemented to increase the rate of fetal survival at delivery of fetuses with congenital life-threatening airway obstructions such as lingual cysts [1], teratomas [2,3], skeletal dysplasia and micrognathia [4], and cystic hygromas, thyroid goiters, and neuroblastomas [5].

The EXIT procedure is conducted in conjunction with an elective Cesarean section. The fetus is only delivered partially from the uterus with maintenance of the uteroplacental circulation. The maintained uteroplacental circulation permits diagnostic and/or therapeutic intervention to secure the fetal airway by means of direct laryngoscopy, fiberoptic bronchoscopy, or tracheostomy. Prerequisites for a successful outcome after the EXIT procedure are complete relaxation of the uterine muscles, maintenance of uterine volume, and uteroplacental circulation [5]. To maintain the uteroplacental circulation, high-dose inhalational anesthetics and/or intravenous nitroglycerin can be used, in contrast to conventional Cesarean section.

The aim of this report is to share our anesthetic experience of the EXIT procedure for the first time with Korean journal of anesthesiology and to highlight the maternal implications of the use of inhalational anesthetics and nitroglycerin during general anesthesia for standard Cesarean section.

Received: April 27, 2010. Revised: 1st, May 15, 2010; 2nd, May 24, 2010. Accepted: June 5, 2010.

Corresponding author: Heeseung Lee, M.D., Department of Anesthesiology and Pain Medicine, School of Medicine, Ewha Womans University, 911-1, Mok 6-dong, Yangcheon-gu, Seoul 158-710, Korea. Tel: 82-2-2650-2670, Fax: 82-2-2655-2924, E-mail: leehee@ewha.ac.kr

(c) This is an open-access article distributed under the terms of the Creative Commons Attribution Non-Commercial License (http:// creativecommons.org/licenses/by-nc/3.0/), which permits unrestricted non-commercial use, distribution, and reproduction in any medium, provided the original work is properly cited. 


\section{Case Report}

The patient was a healthy 29-year-old multigravida. In week 28 , the fetus was found to have an anterior neck mass and polyhydramnios was also detected by prenatal ultrasound. During the last four weeks prior to delivery, the neck mass grew substantially, had a broad base, and was $7 \mathrm{~cm}$ in diameter. An EXIT procedure was performed at week 38 of gestation by a multidisciplinary team of experts including a pediatric otorhinolaryngologist, neonatologist, obstetrician, two anesthesiologists, and nurses. The patient was placed in a supine position with a left lateral tilt to avoid aortocaval compression. An arterial line for continuous arterial pressure monitoring and two peripheral intravenous lines (16-gauge) were placed before induction. Endotracheal intubation (6.5 cuffed) was done after thiopental sodium ( $3 \mathrm{mg} / \mathrm{kg}$ ) and succinylcholine $(1.5 \mathrm{mg} /$ $\mathrm{kg}$ ) administration by a rapid sequence induction. General anesthesia was maintained with sevoflurane $2-3$ vol\% and nitrous oxide in oxygen $(50-50)$ combined with an additional dose of remifentanil $(0.1-0.5 \mu \mathrm{g} / \mathrm{min} / \mathrm{kg})$ and rocuronium (50 $\mathrm{mg}$ in total). An end-tidal (ET) concentration of sevoflurane was maintained at 1-1.5 minimum alveolar concentration (MAC) for proper uterine relaxation until the umbilical cord was clamped. Prior to uterine incision, the patient was given two boluses of intravenous nitroglycerine $(30 \mu \mathrm{g})$, followed by an infusion at $0.5-1 \mu \mathrm{g} / \mathrm{kg} / \mathrm{min}$ to ensure uterine relaxation. To maintain a maternal systolic blood pressure of 100-120 $\mathrm{mmHg}$, the following treatments were required: four boluses of intravenous phenylephrine $(50 \mu \mathrm{g})$, followed by an infusion at $0.05-0.1 \mu \mathrm{g} /$ $\mathrm{kg} / \mathrm{min}$, an infusion of dopamine at $5 \mu \mathrm{g} / \mathrm{kg} / \mathrm{min}$, and rapid infusion of volume expander $(500 \mathrm{ml})$. The skin incision to uterotomy required $22 \mathrm{~min}$. At the time of uterine incision, the obstetrician confirmed that the uterus was fully relaxed and

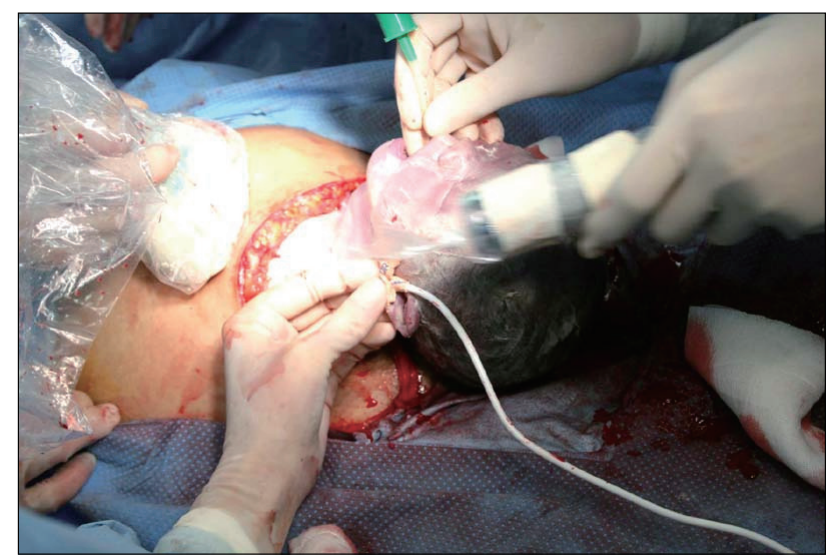

Fig. 1. Management of a potentially difficult neonatal airway on placental support during the ex utero intrapartum treatment (EXIT) procedure. Laryngoscopy and endotracheal intubation were performed on the partially delivered fetus. inserted an angiocatheter (20-gauge) into the uterus under the guidance of ultrasound for decompression by slow reduction of the amniotic fluid volume. A uterine incision stapling device was used to reduce intraoperative maternal blood loss. Then, the fetal head and the part of the torso just above the nipple were partially delivered. A sterile pulse oxymetry was applied at the left ear lobe of the fetus after removal of amniotic fluid, but reliable readings could not be obtained. Ultrasound-guided monitoring was done by an obstetrician for the early detection of placental detachment until the fetal airway was secured. The fetus was intubated with a 2.5 endotracheal tube by a pediatric anesthesiologist at the second attempt (Fig. 1). In the first attempt, the stylet of the endotracheal tube was not removed by an assistant due to the slipperiness of the vernix caseosa. The position of the endotracheal tube was confirmed by a sterile end-tidal $\mathrm{CO}_{2}$ monitor. Once the fetal airway was established and the positive-pressure ventilation was satisfactory, the umbilical cord was severed and the neonate was fully delivered from the uterus. Additional resuscitative efforts for the neonate were not required. The time between uterine incision to cord clamp was about $7 \mathrm{~min}$. The 1-min Apgar score of the neonate was 7 ; the 5 -min score was 9 . After delivery, the infusions of nitroglycerine, dopamine, and phenylephrine were all discontinued, and the ET concentration of sevoflurane was also lowered to $0.8-1.0 \mathrm{vol} \%$. Then, five units of oxytocin were injected intravenously by bolus, and 20 units/L was infused continuously. There were no bleeding problems after delivery of the neonate. The total operation time was $1 \mathrm{~h} 55 \mathrm{~min}$. The estimated blood loss was $1,100 \mathrm{ml}$. The total intake of fluid during the operation was $1,800 \mathrm{ml}$. Both mother and neonate tolerated the EXIT procedure well. Three days later, the neck

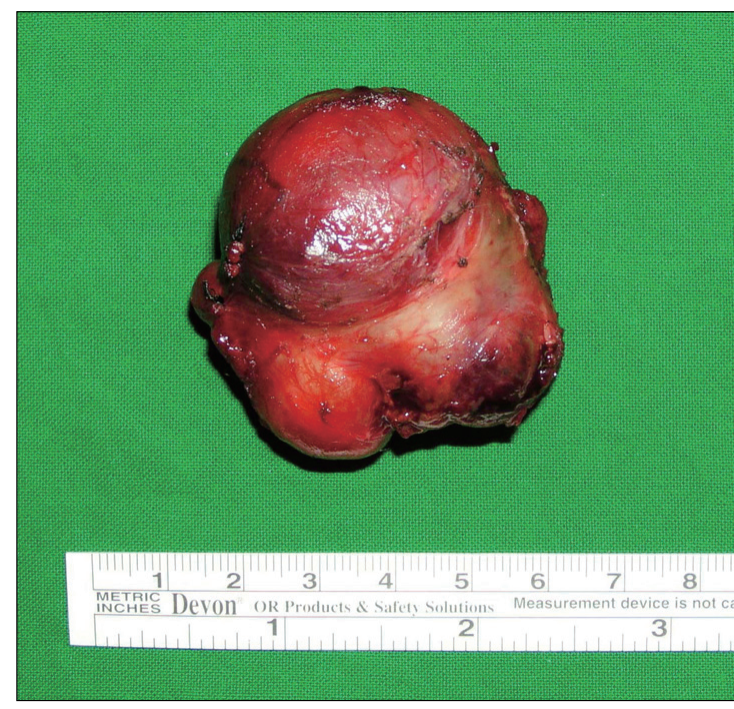

Fig. 2. The mass excised from the neonate, which was diagnosed as a benign teratoma. 
mass of the neonate was completely excised by a pediatric otorhinolaryngologist. The excised mass was confirmed to be a $5 \times 5 \times 5 \mathrm{~cm}$ benign teratoma (Fig. 2 ).

\section{Discussion}

The aim of the EXIT procedure is to manage life-threatening neonatal emergencies and thereby increase the survival rate at delivery. The EXIT procedure therefore requires a multidisciplinary team approach, including at least two anesthesiologists for both the mother and the fetus, a pediatric otorhinolaryngologist, an obstetric surgeon, a neonatologist, and a team of nurses [5].

During the EXIT procedure, anesthesiologists have to maintain the uteroplacental circulation during Cesarean section to increase the time available to secure a potentially obstructed fetal airway. In conventional Cesarean section, the major goals are to minimize the time from anesthetic induction to umbilical cord clamping, thereby minimizing fetal exposure to inhalational anesthetics. This minimizes newborn depression and maternal hemorrhage. In contrast, fetal depression is not a consideration during the EXIT procedure. In fact, during the EXIT procedure, even intramuscular administration of drug cocktails and/or inhalational anesthetics (1-1.5 MAC) are recommended to ensure a motionless, well-anesthetized fetus [6]. Furthermore, there is no need to limit the time of anesthesia induction or the skin incision to delivery time.

The anesthetic goals and principles for an EXIT procedure differ markedly from those for a conventional Cesarean section with respect to maintaining the uteroplacental circulation until the time of secured delivery. First, deep inhalational anesthetics (1.5-3 MAC) are often used to relax the uterine muscles and to maintain the uteroplacental circulation [7]. Inhalational anesthetic concentrations of at least 2 MAC are usually recommended for proper relaxation of the uterine muscles and to prevent early placenta detachment $[6,8]$. For rapid onset and offset of tocolytic action during the EXIT procedure, sevoflurane or desflurane are recommended. Second, tocolytic intravenous drugs can also be used directly during the EXIT procedure. These drugs include nitroglycerine and magnesium sulfate. However, nitroglycerin is a better choice than magnesium sulfate because nitroglycerin is easily titratable and short acting. The onset of uterine relaxation using nitroglycerin is $30-60 \mathrm{~s}$, and a loading bolus of $100 \mu \mathrm{g}$ with continuous dosing of $0.5-$ $1 \mu \mathrm{g} / \mathrm{kg} / \mathrm{min}$ is recommended, as needed, to maintain effective uterine relaxation $[9,10]$. Lastly, dopamine $(5 \mu \mathrm{g} / \mathrm{kg} / \mathrm{min})$, phenylephrine $(0.05-0.1 \mu \mathrm{g} / \mathrm{kg} / \mathrm{min}$ ), and ephedrine bolus (5$10 \mathrm{mg}$ ) can be utilized to maintain the maternal hemodynamics $[11,12]$. Many of the suggested anesthetic maneuvers used during the EXIT procedure to enhance uterine relaxation, such as the use of higher MAC inhalational anesthetics combined with short acting tocolytics, potentially decrease maternal blood pressure and uteroplacental perfusion before delivery, and may lead to uterine atony and continued hemorrhage post-delivery [13]. Meticulous on- and off-techniques are critical to achieve full relaxation of the uterus before delivery and to ensure proper contraction to prevent uterine atony and massive hemorrhage post-delivery.

Diverse anesthetic methods can be used during the EXIT procedure. In our case, sevoflurane (1-1.5 MAC) and remifentanil $(0.1-0.5 \mu \mathrm{g} / \mathrm{kg} / \mathrm{min})$ were used to maintain anesthesia. The ET concentration of sevoflurane was less than 2 MAC before the uterine incision, even though the concentration was set from the beginning of anesthetic induction. In addition, 30 $\mu \mathrm{g}$ nitroglycerine was given to the patient. Palpation by the obstetrician surgeon confirmed that the uterine relaxation was still insufficient. Therefore, an additional bolus of nitroglycerine $(30 \mu \mathrm{g})$ was given and infused continuously at $0.5-1 \mu \mathrm{g} / \mathrm{kg} / \mathrm{min}$. The uteroplacental circulation was maintained for $7 \mathrm{~min}$ (from uterine incision to cord clamping) without maternal or fetal accident until the fetus was intubated and the endotracheal tube was confirmed to be in the correct position. Usually, during the EXIT procedure, the dose of nitroglycerine used in the combined spinal epidural anesthesia is more than $100 \mu \mathrm{g}$ in a bolus [10], and the ET concentration of inhalational anesthetics used in general anesthesia is above 2 MAC $[11,12,14,15]$. In our case, we performed general anesthesia using a lower bolus dose (two consecutive doses of $30 \mu \mathrm{g}$ ) of nitroglycerine and a lower ET concentration of inhalational anesthetics (1-1.5 MAC) to maintain maternal hemodynamic stability and ensure fetal airway safety.

The EXIT procedure is a relatively new procedure and holds promise for newborns with airway obstruction. Anesthesia for the EXIT procedure can be performed in various ways, as long as uterine relaxation and uteroplacental circulation are maintained until the fetal airway is secured. Preoperative planning and communication with regard to anesthesia are the most important factors for success.

\section{References}

1. Schwartz DA, Moriaty KP, Tashjian DB, Wool RS, Parker RK, Markenson GR, et al. Anesthetic management of the exit (ex utero intrapartum treatment) procedure. J Clin Anesth 2001; 13: 387-91.

2. Eschertzhuber S, Keller C, Mitterschiffthaler G, Jochberger S, Kühbacher G. Verifying correct endotracheal intubation by measurement of end-tidal carbon dioxide during an ex utero intrapartum treatment procedure. Anesth Analg 2005; 101: 658-60.

3. Hullett BJ, Shine NP, Chambers NA. Airway management of three cases of congenital cervical teratoma. Paediatr Anaesth 2006; 16: 794-8. 
4. George RB, Melnick AH, Rose EC, Habib AS. Case series: combined spinal epidural anesthesia for Cesarean delivery and ex utero intrapartum treatment procedure. Can J Anaesth 2007; 54: 218-22.

5. Zadra N, Giusti F, Midrio P. Ex utero intrapartum surgery (EXIT): indications and anaesthetic management. Best Pract Res Clin Anaesthesiol 2004; 18: 259-71.

6. Lee IH, Kim DY, Chung RK, Kim CH. Maternal and neonatal effects of sevoflurane and desflurane in cesarean section. Korean J Anesthesiol 2008; 55: 446-51.

7. Dahlgren G, Törnberg DC, Pregner K, Irestedt L. Four cases of the ex utero intrapartum treatment (EXIT) procedure: anesthetic implications. Int J Obstet Anesth 2004; 13: 178-82.

8. Ducloy-Bouthors AS, Marciniak B, Vaast P, Fayoux P, HoufflinDebarge V, Fily A, et al. Maternal and foetal anaesthesia for ex utero intrapartum treatment (EXIT) procedure. Ann Fr Anesth Reanim 2006; 25: 638-43.

9. MacKenzie TC, Crombleholme TM, Flake AW. The ex-utero intrapartum treatment. Curr Opin Pediatr 2002; 14: 453-8.

10. Clark KD, Viscomi CM, Lowell J, Chien EK. Nitroglycerin for relaxation to establish a fetal airway (EXIT procedure). Obstet Gynecol 2004; 103: 1113-5.

11. George RB, Melnick AH, Rose EC, Habib AS. Case series: combined spinal epidural anesthesia for Cesarean delivery and ex utero intrapartum treatment procedure. Can J Anaesth 2007; 54: 218-22.

12. Kuczkowski KM. Ex utero intrapartum treatment (EXIT) procedure versus standard cesarean section. Ann Fr Anesth Reanim 2007; 26: 1003-4.

13. Stevens GH, Schoot BC, Smets MJ, Kremer B, Manni JJ, Gavilanes AW, et al. The ex utero intrapartum treatment (EXIT) procedure in fetal neck masses: a case report and review of the literature. Eur J Obstet Gynecol Reprod Biol 2002; 100: 246-50.

14. Chang LC, Kuczkowski KM. The ex utero intrapartum treatment procedure: anesthetic considerations. Arch Gynecol Obstet 2008; 277: 83-5.

15. Kuczkowski KM. Advances in obstetric anesthesia: anesthesia for fetal intrapartum operations on placental support. J Anesth 2007; 21: 243-51. 